\title{
Intrauterine nutrition: long-term consequences for vascular health
}

This article was published in the following Dove Press journal:

International Journal of Women's Health

II July 2014

Number of times this article has been viewed

\section{Dorota Szostak-Wegierek}

Department of Human Nutrition, Medical University of Warsaw, Warsaw, Poland

Video abstract

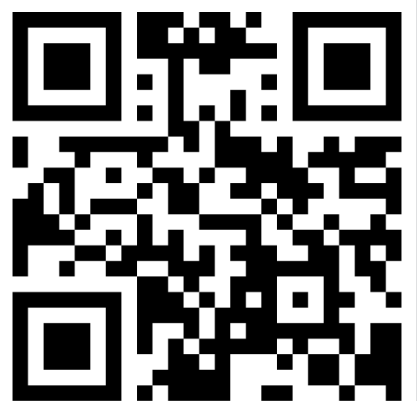

Point your SmartPhone at the code above. If you have a QR code reader the video abstract will appear. Or use: http://dvpr.es/lpQuMbR
Correspondence: Dorota SzostakWegierek

Department of Human Nutrition, Medical University of Warsaw, Erazma Ciołka 27, 0I-445 Warsaw, Poland Tel +48608675995

Email dorota.szostak-wegierek@wum. edu.pl
Abstract: There is a growing body of evidence that improper intrauterine nutrition may negatively influence vascular health in later life. Maternal malnutrition may result in intrauterine growth retardation and, in turn, metabolic disorders such as insulin resistance, diabetes, hypertension, and dyslipidemia, and also enhanced risk of atherosclerosis and cardiovascular death in the offspring. Energy and/or protein restriction is the most critical determinant for fetal programming. However, it has also been proposed that intrauterine n-3 fatty acid deficiency may be linked to later higher blood pressure levels and reduced insulin sensitivity. Moreover, it has been shown that inadequate supply of micronutrients such as folate, vitamin B12, vitamin A, iron, magnesium, zinc, and calcium may contribute to impaired vascular health in the progeny. In addition, hypertensive disorders of pregnancy that are linked to impaired placental blood flow and suboptimal fetal nutrition may also contribute to intrauterine growth retardation and aggravated cardiovascular risk in the offspring. On the other hand, maternal overnutrition, which often contributes to obesity and/or diabetes, may result in macrosomia and enhanced cardiometabolic risk in the offspring. Progeny of obese and/or diabetic mothers are relatively more prone to develop obesity, insulin resistance, diabetes, and hypertension. It was demonstrated that they may have permanently enhanced appetites. Their atheromatous lesions are usually more pronounced. It seems that, particularly, a maternal high-fat/junk food diet may be detrimental for vascular health in the offspring. Fetal exposure to excessive levels of saturated fatty and/or n- 6 fatty acids, sucrose, fructose and salt, as well as a maternal high glycemic index diet, may also contribute to later enhanced cardiometabolic risk.

Keywords: maternal malnutrition, intrauterine growth retardation, maternal overnutrition, macrosomia, adult cardiovascular disease

\section{Introduction}

There is a growing body of evidence that improper intrauterine nutrition may negatively influence vascular health in later life. It concerns both undernutrition and overnutrition. Fetal undernutrition may result from maternal malnutrition or placental dysfunction that is often related to hypertensive disorders of pregnancy or poorly controlled maternal diabetes. The most common reasons for intrauterine overnutrition are maternal excessive nutrient intake and maternal diabetes. Imbalanced intrauterine nutrition seems to influence vascular health in the offspring by both an increase in their cardiometabolic risk factors and direct influence on vascular structure and function.

\section{Maternal malnutrition}

Inadequate birth weight is regarded as a surrogate measure of poor fetal nutritional status. It has been shown that maternal malnutrition, defined as prepregnancy 
underweight and/or insufficient body mass gain during gestation, may result in intrauterine growth retardation (IUGR). ${ }^{1}$ This was also confirmed in our study. ${ }^{2}$ Underweight women gave birth to significantly smaller babies than those whose body mass before pregnancy was normal or excessive. The mean birth weight of the offspring of undernourished mothers was about $300 \mathrm{~g}$ lower than that of the progeny of mothers with normal body mass and about $600 \mathrm{~g}$ lower than that of babies of overweight mothers. The mean birth weight of newborns of women who did not meet Institute of Medicine recommendations concerning weight gain during pregnancy was about $350 \mathrm{~g}$ lower than that of the offspring of mothers with adequate weight gain.

In the last three decades many epidemiological studies have documented the association between fetal growth restriction and the prevalence of cardiovascular risk factors, hypertension, insulin resistance, type 2 diabetes, and cardiovascular deaths. ${ }^{3,4}$ In addition, it was shown that IUGR may be related to such vascular abnormalities as stiffness of abdominal aorta, ${ }^{5}$ reduced arterial compliance, ${ }^{6}$ narrower retinal arteriolar caliber, ${ }^{7}$ and endothelial dysfunction. ${ }^{8-11}$ Martyn et $\mathrm{al}^{12}$ demonstrated a strong inverse relationship between birth weight and the risk of carotid atherosclerosis in elderly subjects. Also, our investigation confirmed these observations. ${ }^{13}$ In 110 young males aged 27-32 years we found that those with a higher value of carotid intima media thickness (CIMT) $(>0.6 \mathrm{~mm}$ versus $[\mathrm{vs}] \leq 0.6 \mathrm{~mm})$ were born with significantly lower birth weights (median 3,380 g vs $3525 \mathrm{~g}, P=0.001)$. This relationship was independent of classic risk factors and the presence of metabolic syndrome, which suggests that the association is more complex. In a recent study, IUGR fetuses demonstrated echocardiographic abnormalities that predicted postnatal hypertension and arterial remodeling already at the age of 6 months. ${ }^{14}$

The relationship between inadequate maternal diet and enhanced cardiovascular risk in the progeny has been documented in many studies. Subjects who were exposed to severe nutritional restriction during their intrauterine period of life at the time of the Dutch or Chinese famine, in comparison with those who did not suffer from substantial nutrient limitations, had a more atherogenic lipid profile, raised prevalence of glucose intolerance, hypertension, preference for a high-fat diet, overweight, and ischemic heart disease. ${ }^{15-20}$

It seems that restrictions of energy and protein supply are the most critical for fetal programming. It was shown in 9-year-old children that relatively low maternal energy intake during pregnancy may increase their risk of atherosclerosis. The mean CIMT value of subjects whose mothers were in the lowest quarter of energy intake in the later stage of pregnancy was significantly higher in comparison with that in children whose mothers were in the highest quarter. ${ }^{21}$ In another study, performed in 24-year-old adults, it was shown that maternal protein intake during the first trimester of gestation was negatively correlated with CIMT value in the progeny. ${ }^{22}$

It was demonstrated in many studies that maternal protein restriction may contribute to IUGR in the progeny and to obesity and type 2 diabetes in their adult life. ${ }^{23}$ In populations with a high prevalence of undernutrition (eg, in India) low birth weight is very common. Subjects whose intrauterine development was restricted usually have relatively increased visceral fat mass and often develop hyperinsulinemia and type 2 diabetes in adult life. ${ }^{24}$ The phenomenon is probably related to insufficient protein energy supply during their fetal life, as it was shown that proper supplementation of malnourished pregnant women with preparations containing high amounts of energy and protein may prevent fetal growth restriction in the progeny. ${ }^{25,26}$

Epidemiological observations were confirmed by animal studies. It was shown that serious energy restriction in pregnant dams resulted in their offspring having reduced birth weights, enhanced food intake during early development, and also obesity and hypoactivity in later life. ${ }^{23}$ On the other hand, an energy- or protein-restricted maternal diet may contribute to decreased insulin secretion, increased insulin resistance, endothelial dysfunction, hypertension, and reduced nephron number in the progeny, ${ }^{21,27,28}$ and also to their hyperleptinemia and hyperphagia. ${ }^{24}$

Mechanistic investigations performed in animal models showed that maternal protein restriction may result in decreased pancreatic $\beta$-cell mass, and subsequently in reduction of insulin secretory response to glucose and amino acids in the offspring. It may also alter metabolic activity of the fetal liver, which may contribute to type 2 diabetes development: ie, increase phosphoenolpyruvate carboxykinase activity, a key enzyme in gluconeogenesis, and decrease glycolytic glucokinase level. These disturbances persist into postnatal life. ${ }^{29}$ In a recent study it was demonstrated that enhanced gluconeogenesis in prenatally protein-restricted animals may be the consequence of impaired activity of liver $\mathrm{X}$ receptor $\alpha$, which inhibits critical genes involved in gluconeogenesis, including G6pase, 11 $\beta$-Hsd1, and phosphoenolpyruvate carboxykinase. Their enhanced expression may result in glucose intolerance in adult life. ${ }^{30}$

Increased diabetes risk in the progeny of protein-restricted dams may also result from their declined skeletal muscle mass and reduced insulin-stimulated muscle glucose uptake. 
This effect is probably mediated by the decreased activity of zeta-isoform of protein kinase $\mathrm{C}$ in muscle cells. ${ }^{29}$ In a recent study it was shown in IUGR pigs that their total number of muscle fibers was lower when compared with normal body weight animals. ${ }^{31}$ In addition, expression of 37 proteins was altered. It concerned those involved in proliferation and differentiation of muscle fibers, energy supply, protein metabolism, nutrient transport, intracellular environment, and tissue integrity.

Maternal protein restriction during pregnancy may also influence adipose tissue metabolism. It was shown in animals that intrauterine protein restriction may impair antilipolytic action of insulin in epididymal and intra-abdominal adipocytes, ${ }^{29}$ which may be followed by elevation of serum free fatty acid level and, in turn, hypertriglyceridemia.

Protein restriction during fetal development may also result in a permanent increase in the activity of hypothalamicpituitary-adrenal axis, ${ }^{32}$ which may contribute to abdominal fat distribution and, as a consequence, metabolic syndrome in adult life. It was also shown that inadequate intrauterine protein supply may alter kidney development, ${ }^{32}$ which may contribute to arterial hypertension. It was postulated that this effect may be mediated by impaired activity of placental 11- $\beta$-hydroxysteroid dehydrogenase 2 enzyme, which is involved in inactivation of glucocorticoids. This, in turn, may result in elevation of the passage of maternal glucocorticoids to the fetus and its enhanced steroid exposure. ${ }^{32}$ In addition, a maternal protein-restricted diet may influence food preferences in the progeny, enhancing preference to a high-fat diet, ${ }^{33}$ which may promote obesity.

It was suggested that intrauterine inadequate nutrition may also program later hypertension through enhanced sympathoadrenal response and increased activity of the renin-angiotensin system (RAS) ${ }^{34}$ In experimental studies, protein deprivation in pregnant dams resulted in raised expression of angiotensin II receptors in the off spring brain regions that are responsible for cardiovascular regulation. Central activation of RAS produces increased renal sympathetic activity and, as a consequence, elevated sodium reabsorption. This, in turn, may contribute to raised blood pressure. ${ }^{35}$ Some authors have proposed that the hypertensive effect of maternal protein restriction may be mediated also by reduced vasodilation ${ }^{36}$ and by decreased glycine generation. ${ }^{34}$

As well as adequate intake of energy and protein, a proper dietary balance of polyunsaturated fatty acids seems to play a crucial role in normal fetal development. It was proposed that n-3 fatty acid (n-3 FA) deficiency may be associated with IUGR.$^{37}$ This effect is probably linked to its influence on placental blood flow. ${ }^{38}$ It should be pointed out that relative deficiency of n-3 FA may result from exposure to excessive levels of trans fatty acids (TFAs), as TFAs may suppress n-3 FA metabolism. It was demonstrated that TFAs may increase the risk of IUGR. ${ }^{39}$

The relationship between maternal n-3 FA intake and later cardiovascular health in the progeny is not clear, but it was found that intrauterine docosahexaenoic acid (DHA) deficiency may be linked to later higher blood pressure levels. ${ }^{40}$ In addition, it was shown that low cord plasma levels of DHA were associated with reduced insulin sensitivity in fetuses of gestational diabetic mothers. ${ }^{41}$

Also, adequate maternal intake of vitamins and minerals is of importance in cardiometabolic prevention in the offspring. Some micronutrient deficiencies may contribute to IUGR. It concerns, among others, folate, which is crucial for synthesis of nucleic acids and cellular division, ${ }^{42}$ and vitamin B12. ${ }^{43}$ The role of these vitamins in fetal programming is complex. In human infants, adequate maternal folate supply, paired with deficiency of vitamin B12, was linked to increased adiposity and insulin resistance. The latter was the most pronounced in the offspring of women characterized by the lowest B12 status and the highest folate concentrations. This micronutrient pattern concerned vegans and those who used folic acid supplementation. ${ }^{43}$ It is of interest to note that in a recent animal study, maternal vitamin B12 and folate restrictions were related to increased visceral fat content in the offspring. ${ }^{44}$ Thus, the link between maternal status of these vitamins and the subsequent metabolic risk in the progeny is not clear.

Inadequate folate intake may also result in enhanced risk of hypertension. This is probably related to reduced glycine generation under condition of low folate status. The fetus is supplied with glycine, which is derived from placental transamination of serine, a process that is influenced by folate. Thus, restricted folate availability may result in reduced glycine production and, subsequently, increased risk of hypertension in the progeny. ${ }^{34}$

Numerous observations suggest also that inadequate maternal intake of other micronutrients such as vitamin A, thiamine, iron, zinc, and magnesium may result in IUGR. ${ }^{45,46}$ However, there are few studies concerning their role in programming of cardiovascular risk. It was shown in animal investigations that intrauterine vitamin A deficiency may be linked to later decreased nephron number and subsequent hypertension ${ }^{47}$ and also to glucose intolerance, ${ }^{48}$ iron restriction to changes in renal morphology ${ }^{49}$ and hypertension 
in the offspring, ${ }^{32}$ and magnesium restriction to decreased insulin sensitivity, impaired glucose tolerance, and increased adiposity. $^{50}$

However, there are a few reports concerning the role of zinc deficiency in fetal programming. It was demonstrated in experimental studies that intrauterine exposure to zinc restriction may contribute to elevated arterial blood pressure and kidney lesions in later life. Among the renal disturbances, decreased number and size of nephrons and the related reduced glomerular filtration rate, as well as proteinuria and raised renal apoptosis and fibrosis, were observed. ${ }^{51,52}$ In addition, intrauterine zinc deficiency may contribute to decreased insulin sensitivity and augmented weight gain in later life. ${ }^{53}$

Zinc, similarly to folate, plays an important role in the synthesis of nucleic acids and cellular divisions, and in this mechanism its deficiency may contribute to growth retardation. In addition, it was reported that maternal zinc restriction, as well as that of copper and vitamin E, may result in decreased placental $11 \beta$-hydroxysteroid dehydrogenase-2 activity. As this enzyme defends the fetus against the influence of maternal glucocorticoid exposure, zinc deficiency may result in enhanced fetal steroid exposure and, as a consequence, decreased birth weight and increased systolic blood pressure and insulin concentrations. ${ }^{54}$

It was also shown in a rat model that inadequate maternal calcium intake may play a role in hypertension programming, ${ }^{55}$ and also in increased insulin resistance and adiposity in the offspring. ${ }^{56}$ In humans, calcium supplementation during pregnancy was linked to reduced blood pressure in the progeny. ${ }^{57,58}$ Maternal vitamin D deficiency may, in turn, contribute to decreased insulin sensitivity. ${ }^{59}$

\section{Hypertensive disorders of pregnancy}

Hypertensive disorders of pregnancy (HDPs) include pregnancy-induced hypertension and pre-eclampsia. They both may coexist with chronic hypertension. HDPs result in dysfunction of both systemic and placental blood vessels. Vascular abnormalities of the placenta are linked to fetal hypoxia and malnutrition and, in turn, IUGR. Among HDP risk factors there are maternal cardiovascular and metabolic syndrome-like disorders that lead to placental and systemic inflammation and oxidative stress. ${ }^{60}$

Gestational hypertension may enhance cardiovascular risk in the offspring. Mogren et $\mathrm{al}^{61}$ observed in a cohort of nearly 8,000 Swedes the relationship between maternal HDP and systolic hypertension in nonlow birth weight progeny aged 29-41 years. The odds ratio (OR) was 1.43 (95\% confidence interval [CI]: 1.04-1.97). This observation was confirmed by Vatten et $a 1 .{ }^{62}$ In their study of over 4,000 Norwegian girls aged 13-19 years, in daughters of pre-eclamptic mothers, in comparison with daughters of nonpre-eclamptic mothers, the average systolic blood pressure was $3 \mathrm{mmHg}$ higher.

Maternal HDP may also influence the risk of diabetes in the offspring. In a British cohort of subjects born in 1958, maternal pre-eclampsia was independently related to glycosylated hemoglobin $\geq 6 \%$ at age 45 years with an OR of 1.65 (95\% CI: 1.02-2.69). ${ }^{63}$ This was confirmed in our study of young adults aged 24-29 years. Maternal preeclampsia (defined according to the standards of the 1970s that included edema) was significantly associated with the Homeostatic Model Assessment Insulin Resistance Index (HOMA-IR) in men. In the male offspring of pre-eclamptic mothers, in comparison with the male progeny of nonpreeclamptic mothers, HOMA-IR, adjusted for current body mass index (BMI), was higher (2.6 vs $2.1, P=0.041)$. In the female offspring it was also elevated (1.8 vs 1.5$)$, although this difference was not statistically significant. ${ }^{64}$

In experimental studies using bilateral uterine artery ligation, which reduces blood flow to the fetus to a similar extent as is observed in humans in the case of uteroplacental insufficiency and results in both fetal hypoxia and subnormal nutrition, it was demonstrated that the resulting IUGR was accompanied by reduced $\beta$-cell mass and also postnatal hyperglycemia, hyperinsulinemia, and diabetes. ${ }^{65}$ In a human prospective cohort study ${ }^{66}$ performed in 6,716 mothers and their children, it was shown that higher third trimester umbilical artery vascular resistance was associated with higher childhood adiposity, abdominal fat distribution, and systolic blood pressure at the age of 6 years. The observed relationships were independent of birth weight.

Among the risk factors of pre-eclampsia are obesity, especially of abdominal type, pregestational diabetes, chronic hypertension, and hypercholesterolemia. ${ }^{60,67}$ It seems also that hypertriglyceridemia may predispose to HDP. It was shown that elevated levels of triglycerides (TG) in early pregnancy may predict pre-eclampsia in the later period of gestation. The risk of early-onset pre-eclampsia (before the 36th week of pregnancy) was five times higher in pregnant women with a serum TG level exceeding $2.4 \mathrm{mmol} / \mathrm{L}$ in the 18 th week of pregnancy than in those with a serum TG level lower than $1.5 \mathrm{mmol} / \mathrm{L}{ }^{68}$ This phenomenon may be explained by vascular changes induced by hypertriglyceridemia, which include chronic inflammation, hypercoagulability, and endothelial dysfunction. ${ }^{69}$ 
As HDPs are associated with metabolic disorders typical for metabolic syndrome, it seems justifiable to propose that nutritional habits that result in obesity and related disturbances may also lead to gestational hypertension among them are overconsumption of energy, fats, sucrose, fructose, and TFAs. Also, the roles of a low intake of fiber, folate, vitamin B12, vitamin D, vitamin A, antioxidants, calcium, zinc, and magnesium are often discussed. ${ }^{70,71}$ It seems that in the prevention of pre-eclampsia a model of nutrition similar to a Mediterranean/Dietary Approaches to Stop Hypertension diet may be effective. A Norwegian cohort study performed in 23,423 females demonstrated that a nutritional pattern characterized by a high intake of vegetables, fruits, plant foods, and vegetable oils was related to a significant decrease in the risk of pre-eclampsia, while dietary patterns rich in meat, sugary drinks, and salty snacks increased this risk. $^{72}$

\section{Maternal overweight and diabetes}

Another problem is maternal overnutrition. It may result not only in hypertensive disorders of pregnancy but also in maternal overweight and diabetes and in macrosomia in the offspring. A growing body of evidence has demonstrated that a high birth weight significantly increases the risk of diabetes and cardiovascular diseases in adult life. It is related to the later tendency for developing overweight and obesity, glucose intolerance, insulin resistance, and impaired insulin secretion. The relationship between maternal obesity and obesity risk in the progeny is well documented. ${ }^{73}$

The mechanism underlying influence of maternal adiposity and/or diabetes on fetal overgrowth is not clear. It may be related to greater transfer of glucose, amino acids, and free fatty acids to the fetus. Hyperglycemia stimulates fetal production of insulin, playing a role of fetal growth factor. Also, high levels of maternal, placental, and fetal insulin-like growth factor may contribute to macrosomia. ${ }^{73-78}$

Many authors have observed that a high birth weight predisposes to later overweight and obesity. It was confirmed by the meta-analysis of 66 studies from 26 countries, which included 643,902 persons aged 1-75 years. ${ }^{79}$ Birth weight $>4,000 \mathrm{~g}$ was related to overweight, with an OR of 1.66 (95\% CI: $1.55-1.77)$.

The relationship between overweight and cardiometabolic risk is well known, and it seems reasonable that maternal adiposity resulting in macrosomia in the offspring, which, in turn, is related to the later overweight, may contribute to the increased susceptibility to vascular disease in their adult life. This concept was supported by a prospective cohort study performed in 1,400 young adults born in Jerusalem. ${ }^{80}$ It was shown that both maternal prepregnancy BMI and gestational weight gain were independently related to their cardiometabolic risk. Greater maternal prepregnancy adiposity was associated with higher offspring BMI, waist circumference, systolic and diastolic blood pressures, insulin, and TG levels, and with lower high-density lipoprotein cholesterol concentrations. Higher maternal gestational weight gain was related to the increased BMI and waist circumference in the progeny.

It was postulated that the increased risk of adiposity in the offspring of overweight and diabetic mothers may result from their permanent changes in appetite control. ${ }^{77}$ Increased fetal insulin levels are probably associated with dysplasia of the ventromedial hypothalamic nucleus, which is followed by persistent hypothalamic resistance to the peripheral signals of insulin and leptin. It was demonstrated that activity of neurons responsible for secretion of orexigenic peptides such as galanin and neuropeptide $\mathrm{Y}$ was increased. This may, in turn, contribute to hyperphagia, overweight, and abnormal carbohydrate metabolism. ${ }^{77}$ Also, fetal hyperleptinemia may be involved in the central malprogramming of energy homeostasis. High fetal levels of leptin probably originate both from its oversecretion by the obese mother and from its overproduction by the placenta under conditions of insulin treatment of maternal diabetes. ${ }^{81}$

In addition to increased susceptibility to overweight, maternal diabetes may be related to early vascular pathology in the offspring. It was shown that macrosomic newborns of diabetic mothers had increased aortic IMT. ${ }^{76}$ It was proposed that this phenomenon may be related to fetal dyslipidemia, elevated levels of insulin-like growth factor 1 , and enhanced chronic inflammation. . $^{76,82}$

Another problem is the transgenerational transmission of diabetes risk. As has been described, maternal diabetes often results in macrosomia in the progeny. However, in some cases of gestational diabetes, fetal insulin resistance may develop. This may attenuate a trophic effect of insulin and result in IUGR. ${ }^{83}$ Both micro- and macrosomia may contribute to enhanced diabetes risk in the offspring. In the case of female progeny, gestational diabetes may occur in the second generation and, in turn, increase diabetes risk in the offspring of subsequent generations. Hence, diabetes risk may be transmitted from mothers to daughters independently of genetic heritage. ${ }^{84}$

As has been described, maternal excessive nutrition may increase cardiometabolic risk in the offspring. Human studies have demonstrated that maternal obesity may result 
in fetal hyperinsulinemia ${ }^{85}$ and affect insulin sensitivity in the offspring. ${ }^{86}$ Also, a positive relationship between gestational weight gain and obesity and systolic blood pressure in the progeny was demonstrated. ${ }^{73}$ In animal studies, progeny of obese dams exhibited impaired endothelial function, altered vascular fatty acid content, increased aortic stiffness, and hypertension. Smooth muscle cell number was reduced, and cardiovascular response to stress was increased. ${ }^{73}$ It was postulated that maternal obesity may contribute to alterations in the adipose tissue in the offspring. The proposed changes concern proliferation and differentiation of adipocytes, expression of inflammatory cytokines, and lipid metabolism. $^{73}$

There are a few reports on the effect of a maternal junk food diet (rich in fat, sugar, and salt) on cardiometabolic risk in the progeny. In experimental studies performed in rats, this sort of nutrition during pregnancy and lactation increased the risk of excessive adiposity, blood glucose, insulin, TG, and/or cholesterol levels in the offspring. ${ }^{87}$ It was proposed that intrauterine exposure to junk food may predispose to the later preference for these kind of products, to obesity, ${ }^{88}$ and also to lipid accumulation in skeletal muscles, which is probably an early manifestation of metabolic disturbances. ${ }^{89}$ In addition, a maternal junk food diet may affect physical endurance in the offspring. In animal models, intrauterine exposure to this model of nutrition resulted in muscular lesions in later life. The alterations included increased intramuscular lipid content and semitendinosus muscle atrophy, changed expression of genes that are crucial for muscle growth and metabolism, and subsequent reduced muscle force. ${ }^{90}$

It should be emphasized that there is a growing body of evidence that excessive maternal fat intake plays an important role in fetal programming. It was demonstrated in animal models that intrauterine exposure to a maternal high-fat diet may enhance the later risk of obesity, hyperinsulinemia, hyperglycemia, hypercholesterolemia, hypertriglyceridemia, insulin resistance, metabolic syndrome, hypertension, and endothelial dysfunction, ${ }^{73,91-96}$ and may also result in increased activity of orexigenic peptides, galanin, enkephalin, and dynorphin in the paraventricular nucleus and also orexin, and melanin-concentrating hormone in the perifornical lateral hypothalamus. ${ }^{97}$ The deleterious effects of a high-fat diet may be partially explained by increased oxidative stress. ${ }^{95}$

A maternal high-fat diet may also contribute to an increased risk of nonalcoholic fatty liver disease in the offspring. It was shown in mice that a high-fat diet before and during pregnancy may be related to elevated hepatic TG level in progeny, probably due to the changed activity of mitochondrial electron transport chain complex, as well as a raised expression of genes that take part in lipogenesis, oxidative stress, and inflammation. ${ }^{73}$ In a nonhuman primate model it was demonstrated that a maternal high-fat diet, independent of maternal obesity, may result in impaired uterine blood flow and increased placental inflammation. It was observed that TG content and oxidative stress in the fetal liver were raised, ${ }^{98,99}$ and expression of gluconeogenic enzymes and transcription factors was increased..$^{99}$

It was also suggested that maternal high intake of n- 6 fatty acids may contribute to obesity, hepatic insulin resistance, and increased hepatic lipid content in the offspring. ${ }^{81}$ An excess of linoleic acid (LA) may result in increased production of arachidonic acid (AA), which is shown to be adipogenic. It seems probable that a maternal dietary imbalance between n-6 and n-3 polyunsaturated fatty acids may play a role in fetal programming of adiposity. ${ }^{91}$ Eicosanoids produced from AA take part in differentiation of adipocytes through the influence on peroxisome proliferator-activated receptor $\gamma \cdot{ }^{100}$ It was shown in rats that they also decrease insulin-stimulated adipocyte leptin secretion. ${ }^{100}$ On the other hand, eicosapentaenoic acid and DHA increased leptin production in adult male rats. ${ }^{100}$ It was also reported that a high LA/low alpha-linolenic acid diet over four generations was linked to a progressive increase in adiposity. ${ }^{100}$ In addition, a high eicosapentaenoic acid and DHA/ low LA diet fed in rats was shown to increase hypothalamic messenger ribonucleic levels of the anorexigenic cocaine- and amphetamine-regulated transcript (CART) peptide. ${ }^{100}$

In an animal model it was shown that a high intake of saturated fat before and during pregnancy may induce maternal insulin resistance and placental vascular damage. These alterations were probably related to oxidative stress. ${ }^{101}$ In a recent prospective cohort study it was demonstrated that cord plasma levels of saturated fatty acids (stearic and arachidic) were negatively associated with fetal insulin sensitivity. There was no difference in this respect between diabetic and nondiabetic pregnancies. ${ }^{42}$ This may suggest the role of saturated fatty acids in the development of fetal insulin resistance.

Another problem is the amount and sort of consumed carbohydrates. It was shown in humans that maternal high glycemic index of the diet during pregnancy was related to HOMA-IR, insulin, and leptin levels in the progeny at the age of 20 years. ${ }^{102}$ In an animal model, excessive maternal intake of sucrose resulted in higher adiposity, increased hepatic TG content, and elevated serum low-density lipoprotein cholesterol levels in the offspring. ${ }^{103}$ Intrauterine exposure to a fructose diet may, in turn, result in increased fasting insulin and elevated 
leptin and glucose levels in later life. ${ }^{95}$ It may also contribute to obesity, probably because of impairment of endocrine signaling interplay between adipocytes and central nuclei. ${ }^{95}$

Also, fetal exposure to excessive salt intake may play a role in cardiovascular risk programming. It was demonstrated in an animal model that maternal high salt intake during pregnancy affected expression of the renal elements of the RAS system, including angiotensinogen, angiotensin-converting enzyme, and also angiotensin II receptor type 1 , and angiotensin II receptor type 2 . The authors suggest that these changes may contribute to both renal and cardiovascular diseases in adult life. ${ }^{104}$

Maternal overnutrition, especially that concerning saturated fatty acids, trans fatty acids, and cholesterol, and also a low intake of unsaturated fatty acids and fiber, may result in maternal hypercholesterolemia. It was proposed that this maternal condition may program susceptibility to atherosclerosis in the offspring, independently of classic risk factors. ${ }^{105,106}$ It seems that oxidative stress induced by maternal hypercholesterolemia may mediate this effect. It was shown in animals that atherosclerosis in the progeny of hypercholesterolemic mothers may be prevented by both hypolipemic treatment and supplementation with antioxidants during pregnancy. ${ }^{107}$

It is also of interest that intrauterine exposure to a highfat and low-carbohydrate diet, the model of nutrition that became popular in the last decades, may be deleterious for health in later life. It was reported in humans that this sort of maternal diet may result in offspring of reduced birth weight and increased risk of hypertension, increased fasting plasma cortisol levels, and also amplified hypothalamic-pituitaryadrenal responses. ${ }^{108}$

\section{Conclusion}

Summarizing, intrauterine exposure to imbalanced nutrition, both to inadequate and excessive intake of energy and macro- and micronutrients, may contribute to exacerbated cardiovascular risk. A maternal healthy balanced diet during pregnancy seems to play a positive role in fetal programming of vascular health.

\section{Disclosure}

The author reports no conflicts of interest in this work.

\section{References}

1. Kramer MS. The epidemiology of adverse pregnancy outcomes: an overview. J Nutr. 2003;133(5 Suppl 2):1592S-1596S.

2. Szostak-Węgierek D, Szamotulska K, Szponar L. Influence of maternal nutrition on infant birthweight. Ginekol Pol. 2004;75(9):692-698.
3. Szostak-Wegierek D, Szamotulska K. Fetal development and risk of cardiovascular diseases and diabetes type 2 in adult life. Med Wieku Rozwoj. 2011;15(3):203-215.

4. Zhang Z, Kris-Etherton PM, Hartman TJ. Birth weight and risk factors for cardiovascular disease and type 2 diabetes in US Children and adolescents: 10 year results from NHANES. Matern Child Health J. Epub November 16, 2013.

5. Levent E, Atik T, Darcan S, Ulger Z, Gökşen D, Ozyürek AR. The relation of arterial stiffness with intrauterine growth retardation. Pediatr Int. 2009;51(6):807-811.

6. Martyn CN, Barker DJ, Jespersen S, Greenwald S, Osmond C, Berry C. Growth in utero, adult blood pressure, and arterial compliance. Br Heart J. 1995;73(2):116-121.

7. Liew G, Wang JJ, Duncan BB, et al. Atherosclerosis risk in communities study: low birthweight is associated with narrower arterioles in adults. Hypertension. 2008;51(4):933-938.

8. Martin H, Gazelius B, Norman M. Impaired acetylcholine induced vascular relaxation in low birth weight infants: implications for adult hypertension. Pediatr Res. 2000;47(4 Pt 1):457-462.

9. Martin H, Hu J, Gennser G, Norman M. Impaired endothelial function and increased carotid stiffness in 9-year-old children with low birthweight. Circulation. 2000;102(22):2739-2244.

10. Goodfellow J, Bellamy MF, Gorman ST, et al. Endothelial function is impaired in fit young adults of low birth weight. Cardiovasc Res. 1998;40(3):600-606.

11. Serne EH, Stehouwer CD, ter Maaten JC, ter Wee PM, Donker AJ, Gans RO. Birth weight relates to blood pressure and microvascular function in normal subjects. J Hypertens. 2000;18(10):1421-1427.

12. Martyn CN, Gale CR, Jespersen S, Sherriff SB. Impaired fetal growth and atherosclerosis of carotid and peripheral arteries. Lancet. 1998;352(9123):173-178.

13. Szostak-Węgierek D, Szamotulska K, Maj A. Relationship between carotid intima media thickness, atherosclerosis risk factors and birthweight in young males. Kardiol Pol. 2011;69(7):673-678.

14. Cruz-Lemini M, Crispi F, Valenzuela-Alcaraz B, et al. A fetal cardiovascular score to predict infant hypertension and arterial remodeling in intrauterine growth restriction. Am J Obstet Gynecol. 2014;210(6):552.e1-552.e22.

15. Roseboom TJ, van der Meulen JH, Osmond C, Barker DJ, Ravelli AC, Bleker OP. Plasma lipid profiles in adults after prenatal exposure to the Dutch famine. Am J Clin Nutr. 2000;72(5):1101-1106.

16. Kyle UG, Pichard C. The Dutch Famine of 1944-1945: a pathophysiological model of long-term consequences of wasting disease. Curr Opin Clin Nut. Metab Care. 2006;9(4):388-394.

17. Lumey LH, Stein AD, Kahn HS, et al. Cohort profile: the Dutch Hunger Winter families study. Int J Epidemiol. 2007;36(6):1196-1204.

18. Chen H, Nembhard WN, Stockwell HG. Sex-Specific effects of fetal exposure to the 1959-1961 Chinese famine on risk of adult hypertension. Matern Child Health J. 2014;18(3):527-533.

19. Wang PX, Wang JJ, Lei YX, Xiao L, Luo ZC. Impact of fetal and infant exposure to the Chinese Great Famine on the risk of hypertension in adulthood. PLoS One. 2012;7(11):e49720.

20. Lussana F, Painter RC, Ocke MC, Buller HR, Bossuyt PM, Roseboom TJ. Prenatal exposure to the Dutch famine is associated with a preference for fatty foods and a more atherogenic lipid profile. Am $J$ Clin Nutr. 2008;88(6):1648-1652.

21. Gale CR, Jiang B, Robinson SM, Godfrey KM, Law CM, Martyn CN. Maternal diet during pregnancy and carotid intima-media thickness in children. Arterioscler Thromb Vasc Biol. 2006;26(8):1877-1882.

22. Rerkasem $\mathrm{K}$, Wongthanee $\mathrm{A}$, Rerkasem $\mathrm{A}$, et al. Intrauterine nutrition and carotid intimal media thickness in young Thai adults. Asia Pac $J$ Clin Nutr. 2012;21(2):247-252.

23. Levin BE. Metabolic imprinting: critical impact of the perinatal environment on the regulation of energy homeostasis. Phil Trans $R$ Soc B. 2006;361(1471):1107-1121.

24. Vickers MH, Krechowec SO, Breier BH. Is later obesity programmed in utero? Curr Drug Targets. 2007;8(8):923-934. 
25. Jackson AA, Robinson SM. Dietary guidelines for pregnancy: a review of current evidence. Public Health Nutr. 2001;4(2B):625-630.

26. Kramer MS, Kakuma R. Energy and protein intake in pregnancy. Cochrane Database Syst Rev. 2003;4:CD000032.

27. Szamotulska K, Szostak-Wegierek D. Mala masa urodzeniowa a zespol $\mathrm{X}$ w wieku doroslym ("hipoteza Barkera") [Low birth weight and syndrome X in adult life ("Barker hypothesis")]. Diabetologia Polska. 1999;6(1):56-61. Polish.

28. McMillen IC, Robinson JS. Developmental origins of the metabolic syndrome: prediction, plasticity, and programming. Physiol Rev. 2005;85(2):571-633.

29. Martin-Gronert MS, Ozanne SE. Experimental IUGR and later diabetes. J Intern Med. 2007;261(5):437-452.

30. Vo TX, Revesz A, Sohi G, Ma N, Hardy DB. Maternal protein restriction leads to enhanced hepatic gluconeogenic gene expression in adult male rat offspring due to impaired expression of the liver $\mathrm{X}$ receptor. J Endocrinol. 2013;218(1):85-97.

31. Wang T, Liu C, Feng C, et al. IUGR alters muscle fiber development and proteome in fetal pigs. Front Biosci (Landmark Ed). 2013;18: 598-607.

32. Ingelfinger JR. Pathogenesis of perinatal programming. Curr Opin Nephrol Hypertens. 2004;13(4):459-464.

33. Bellinger L, Lilley C, Langley-Evans SC. Prenatal exposure to a maternal low-protein diet programmes a preference for high-fat foods in the young adult rat. Br J Nutr. 2004;92(3):513-520.

34. Gardner DS, Bell RC, Symonds ME. Fetal mechanisms that lead to later hypertension. Curr Drug Targets. 2007;8(8):894-905.

35. Nuyt AM, Alexander BT. Developmental programming and hypertension. Curr Opin Nephrol Hypertens. 2009;18(2):144-152.

36. Brawley L, Itoh $\mathrm{S}$, Torrens $\mathrm{C}$, et al. Dietary protein restriction in pregnancy induces hypertension and vascular defects in rat male offspring. Pediatr Res. 2003;54(1):83-90.

37. Oken E, Kleinman KP, Olsen SF, Rich-Edwards JW, Gillman MW. Associations of seafood and elongated n-3 fatty acid intake with fetal growth and length of gestation: results from a US pregnancy cohort. Am J Epidemiol. 2004;160(8):774-783.

38. Williamson CS. Nutrition in pregnancy. Nutrition Bulletin. 2006; 31(1):28-59.

39. Hornstra G, van Eijsden M, Dirix C, Bonsel G. Trans fatty acids and birth outcome: some first results of the MEFAB and ABCD cohorts. Atheroscler Suppl. 2006;7(2):21-23.

40. Weisinger HS, Armitage JA, Sinclair AJ, Vingrys AJ, Burns PL, Weisinger RS. Perinatal omega-3 deficiency affects blood pressure in later in life. Nat Med. 2001;7(3):258-259.

41. Zhao JP, Levy E, Fraser WD, et al. Circulating docosahexaenoic acid levels are associated with fetal insulin sensitivity. PLoS One. 2014;9(1):e85054.

42. Bolesta M, Szostak-Wegierek D. Zywienie kobiety podczas ciazy. Czesc II. Witaminy i skladniki mineralne [Nutrition during pregnancy. Part II. Vitamins and minerals]. Zyw Czlow Metab. 2009;36(4):656-664. Polish.

43. Yajnik CS, Deshmukh US. Maternal nutrition, intrauterine programming and consequential risks in the offspring. Rev Endocr Metab Disord. 2008;9(3):203-211.

44. Kumar KA, Lalitha A, Pavithra D, et al. Maternal dietary folate and/or vitamin B12 restrctions alter body composition (adiposity) and lipid metabolism in Wistar rat offspring. J Nutr Biochem. 2013;24(1): 25-31.

45. Szostak-Wegierek D. Znaczenie prawidlowego zywienia kobiety w czasie ciazy [Importance of adequate nutrition during pregnancy]. Zyw Czlow Metab. 2004;31(2):160-171. Polish.

46. Beard J. Iron requirements and adverse outcomes. In: Lammi-Keefe CJ, Couch SC, Philipson EH, editors. Handbook of Nutrition in Pregnancy. Totowa, NJ: Humana Press; 2008:233-254.

47. Lelievre-Pegorier M, Vilar J, Ferrier ML, et al. Mild vitamin A deficiency leads to inborn nephron deficit in the rat. Kidney Int. 1998;54(5):1455-1462.
48. Matthews KA, Rhoten WB, Driscoll HK, Chertow BS. Vitamin A deficiency impairs fetal islet development and causes subsequent glucose intolerance in adult rats. J Nutr. 2004;134(8):1958-1963.

49. Lisle SJ, Lewis RM, Petry CJ, Ozanne SE, Hales CN, Forhead AJ. Effect of iron restriction during pregnancy on renal morphology in the adult rat offspring. Br J Nutr. 2003;90(1):33-39.

50. Venu L, Kishore YD, Raghunath M. Maternal and perinatal magnesium restriction predisposes rat pups to insulin resistance and glucose intolerance. J Nutr. 2005;135(6):1353-1358.

51. Tomat AL, Inserra F, Veiras L, et al. Moderate zinc restriction during fetal and postnatal growth of rats: effects on adult arterial blood pressure and kidney. Am J Physiol Regul Integr Comp Physiol. 2008;295(2):R543-R549.

52. Tomat AL, Costa MDLT, Arranz CT. Zinc restriction during different periods of life: influence in renal and cardiovascular diseases. Nutrition. 2011;27(4):392-398.

53. Jou MY, Phillips AF, Lonnerdal B. Maternal zinc deficiency in rats affects growth and glucose metabolism in the offspring by inducing insulin resistance postnatally. J Nutr. 2010;140(9):1621-1627.

54. Rosario JF, Gomez MP, Anbu P. Does the maternal micronutrient deficiency (copper or zinc or vitamin E) modulate the expression of placental 11 beta hydroxysteroid dehydrogenase-2 per se predispose offspring to insulin resistance and hypertension in later life? Indian $J$ Physiol Pharmacol. 2008;52(4):355-365.

55. Bergel E, Belizan JM. A deficient maternal calcium intake during pregnancy increases blood pressure of the offspring in adult rats. BJOG. 2002;109(5):540-545.

56. Venu L, Harishankar N, Krishna TP, Raghunath M. Does maternal dietary mineral restriction per se predispose the offspring to insulin resistance? Eur J Endocrinol. 2004;151(2):287-294.

57. Hiller JE, Crowther CA, Moore VA, Willson K, Robinson JS. Calcium supplementation in pregnancy and its impact on blood pressure in children and women: follow up of a randomised controlled trial. Aust N Z J Obstet Gynaecol. 2007;47(2):115-121.

58. Hawkesworth S. Conference on "Multidisciplinary Approaches to Nutritional Problems". Postgraduate symposium. Exploiting dietary supplementation trials to assess the impact of the prenatal environment on CVD risk. Proc Nutr Soc. 2009;68(1):78-88.

59. Lapillonne A. Vitamin D deficiency during pregnancy may impair maternal and fetal outcomes. Med Hypotheses. 2010;74(1): $71-75$.

60. Magnussen EB, Vatten LJ, Lund-Nilsen TI, Salvesen KA, Davey Smith G, Romundstad PR. Prepregnancy cardiovascular risk factors as predictors of pre-eclampsia: population based cohort study. BMJ. 2007;335(7627):978.

61. Mogren I, Hogberg U, Stegmayr B, Lindhal B, Stenlund H. Fetal exposure, heredity and risk indicators for cardiovascular disease in a Swedish welfare cohort. Int Epidemiol. 2001;30(4):853-862.

62. Vatten LJ, Romundstad PR, Holmen TL, Hsieh CC, Trichopoulos D, Stuver SO. Intrauterine exposure to preeclampsia and adolescent blood pressure, body size, and age at menarche in female offspring. Obstet Gynecol. 2003;101(3):529-533.

63. Thomas C, Hypponen E, Power C. Prenatal exposures and glucose metabolism in adulthood: are effects mediated through birth weight and adiposity? Diabetes Care. 2007;30(4):918-924.

64. Szamotulska K, Szostak-Wegierek D. Insulin sensitivity and secretion in young adults and symptoms of preeclampsia in their mothers. Pediatr Res. 2005;58(5):1093.

65. Tarry-Adkins JL, Ozanne SE. Mechanisms of early life programming: current knowledge and future directions. Am J Clin Nutr. 2011; 94(Suppl 6):1765S-1771S.

66. Gaillard R, Steegers EA, Tiemeier H, Hofman A, Jaddoe VW. Placental vascular dysfunction, fetal and childhood growth, and cardiovascular development: the generation R study. Circulation. 2013;128(20):2202-2210.

67. Barton JR, Sibai BM. Prediction and prevention of recurrent preeclampsia. Obstet Gynecol. 2008;112(2 Pt 1):359-372. 
68. Clausen T, Djurovic S, Henriksen T. Dyslipidemia in early second trimester is mainly a feature of women with early onset pre-eclampsia. BJOG. 2001;108(10):1081-1087.

69. Szostak-Wegierek D. Leczenie hiperlipidemii u kobiet w ciazy. In: Zaburzenia lipidowe [Treatment of hyperlipidemia in pregnancy. In: Lipid disorders.]. Cybulska B, Klosiewicz-Latoszek L, editors. Termedia Wydawnictwa Medyczne. Polska: Poznan; 2010:159-170. Polish.

70. Xu H, Shatenstein B, Luo ZC, Wei S, Fraser W. Role of nutrition in the risk of preeclampsia. Nutr Rev. 2009;67(11):639-657.

71. Barger MK. Maternal nutrition and perinatal outcomes. J Midwifery Womens Health. 2010;55(6):502-511.

72. Brantsaeter AL, Haugen M, Samuelsen SO, et al. A dietary pattern characterized by high intake of vegetables, fruits, and vegetable oils is associated with reduced risk of preeclampsia in nulliparous pregnant Norwegian women. J Nutr. 2009;139(6):1162-1168.

73. Drake AJ, Reynolds RM. Impact of maternal obesity on offspring obesity and cardiometabolic disease risk. Reproduction. 2010;140(3):387-398.

74. Bolesta M, Szostak-Wegierek D. Zywienie kobiety podczas ciazy. Czesc I. Energia i makroskladniki [Nutrition during pregnancy. Part I. Energy and macronutrients]. Zyw Czlow Metab. 2009;36(4):648-655. Polish.

75. Thomas AM. Diabetes and pregnancy. In: Lammi-Keefe CJ, Couch SC, Philipson EH, editors. Handbook of Nutrition in Pregnancy. Totowa, NJ: Humana Press; 2008:233-254.

76. Akcakus M, Koklu E, Baykan A, et al. Macrosomic newborns of diabetic mothers are associated with increased aortic intima-media thickness and lipid concentrations. Horm Res. 2007;67(6):277-283.

77. Plagemann A. A matter of insulin: developmental programming of body weight regulation. J Matern Fetal Neonatal Med. 2008;21(3): 143-148.

78. Jansson T, Cetin I, Powell TL, et al. Placental transport and metabolism in fetal overgrowth: a workshop report. Placenta. 2006;27 Suppl A: S109-S113.

79. Schellong K, Schulz S, Harder T, Plagemann A. Birth weight and longterm overweight risk: systematic review and a meta-analysis including 643,902 persons from 66 studies and 26 countries globally. PLoS One. 2012;7(10):e47776.

80. Hochner H, Friedlander Y, Calderon-Margalit R, et al. Associations of maternal prepregnancy body mass index and gestational weight gain with adult offspring cardiometabolic risk factors: the Jerusalem perinatal family follow-up study. Circulation. 2012;125(11):1381-1389.

81. Levin BE. Metabolic imprinting: critical impact of the perinatal environment on the regulation of energy homeostasis. Philos Trans $R$ Soc Lond B Biol Sci. 2006;361(1471):1107-1121.

82. DeRuiter MC, Alkemade FE, Gittenberger-de Groot AC, Poelmann RE, Havekes LM, van Dijk KW. Maternal transmission of risk for atherosclerosis. Curr Opin Lipidol. 2008;19(4):333-337.

83. Hattersley AT, Tooke JE. The fetal insulin hypothesis: an alternative explanation of the association of low birthweight with diabetes and vascular disease. Lancet. 1999;353(9166):1789-1792.

84. Martin-Gronert MS, Ozanne SE. Experimental IUGR and later diabetes. J Intern Med. 2007;261(5):437-452.

85. HAPO Study Cooperative Research Group. Hyperglycaemia and Adverse Pregnancy Outcome (HAPO) study: associations with maternal body mass index. BJOG. 2010;117(5):575-584.

86. Catalano PM, Presley L, Minium J, Hauguel-de Mouzon S. Fetuses of obese mothers develop insulin resistance in utero. Diabetes Care. 2009;32(6):1076-1080.

87. Bayol SA, Simbi BH, Bertrand JA, Stickland NC. Offspring from mothers fed a 'junk food' diet in pregnancy and lactation exhibit exacerbated adiposity that is more pronounced in females. $J$ Physiol. 2008;586(13):3219-3230.

88. Bayol SA, Farrington SJ, Stickland NC. A maternal 'junk food' diet in pregnancy and lactation promotes an exacerbated taste for 'junk food' and a greater propensity for obesity in rat offspring. Br J Nutr. 2007;98(4):843-851.
89. Bayol SA, Simbi BH, Stickland NC. A maternal cafeteria diet during gestation and lactation promotes adiposity and impairs skeletal muscle development and metabolism in rat offspring at weaning. $J$ Physiol. 2005;567(Pt 3):951-961.

90. Bayol SA, Macharia R, Farrington SJ, Simbi BH, Stickland NC. Evidence that a maternal "junk food" diet during pregnancy and lactation can reduce muscle force in offspring. Eur J Nutr. 2009;48(1):62-65.

91. Reusens B, Ozanne SE, Remacle C. Fetal determinants of type 2 diabetes. Curr Drug Targets. 2007;8(8):935-941.

92. Khan IY, Dekou V, Douglas G, et al. A high-fat diet during rat pregnancy or suckling induces cardiovascular dysfunction in adult offspring. Am J Physiol Regul Integr Comp Physiol. 2005;288(1): R127-R133.

93. Koukkou E, Ghosh P, Lowy C, Poston L. Offspring of normal and diabetic rats fed saturated fat in pregnancy demonstrate vascular dysfunction. Circulation. 1998;98(25):2899-2904.

94. Srinivasan M, Katewa SD, Palaniyappan A, Pandya JD, Patel MS. Maternal high-fat diet consumption results in fetal malprogramming predisposing to the onset of metabolic syndrome-like phenotype in adulthood. Am J Physiol Endocrinol Metab. 2006;291(4): E792-E799.

95. Lakshmy R. Metabolic syndrome: role of maternal undernutrition and fetal programming. Rev Endocr Metab Disord. 2013;14(3): 229-240.

96. Fan L, Lindsley SR, Comstock SM, et al. Maternal high-fat diet impacts endothelial function in nonhuman primate offspring. Int J Obes (Lond). 2013;37(2):254-262.

97. Chang GQ, Gaysinskaya V, Karatayev O, Leibowitz SF. Maternal high-fat diet and fetal programming: increased proliferation of hypothalamic peptide-producing neurons that increase risk for overeating and obesity. J Neurosci. 2008;28(46):12107-12119.

98. Frias AE, Morgan TK, Evansetal AE, et al. Maternal high-fat diet disturbs uteroplacental hemodynamics and increases the frequency of stillbirth in a nonhuman primate model of excess nutrition. Endocrinology. 2011;152(6):2456-2464.

99. McCurdy CE, Bishop JM, Williamsetal SM, et al. Maternal high-fat diet triggers lipotoxicity in the fetal livers of nonhuman primates. J Clin Invest. 2009;119(2):323-335.

100. Innis SM. Metabolic programming of long-term outcomes due to fatty acid nutrition in early life. Matern Child Nutr. 2011;7 Suppl 2: $112-123$.

101. Liang C, DeCourcy K, Prater MR. High-saturated-fat diet induces gestational diabetes and placental vasculopathy in C57BL/6 mice. Metabolism. 2010;59(7):943-950.

102. Danielsen I, Granstro C, Haldorsson T, et al. Dietary glycemic index during pregnancy is associated with biomarkers of the metabolic syndrome in offspring at age 20 years. PLoS One. 2013;8(5):e64887.

103. Sedova L, Seda O, Kazdova L, et al. Sucrose feeding during pregnancy and lactation elicits distinct metabolic response in offspring of an inbred genetic model of metabolic syndrome. Am J Physiol Endocrinol Metab. 2007;292(5):E1318-E1324.

104. Mao C, Liu R, Bo L, et al. High-salt diets during pregnancy affected fetal and offspring renal renin-angiotensin system. J Endocrinol. 2013;218(1):61-73.

105. Napoli C, D'Armiento FP, Mancini FP, et al. Fatty streak formation occurs in human fetal aortas and is greatly enhanced by maternal hypercholesterolemia. Intimal accumulation of low density lipoprotein and its oxidation precede monocyte recruitment into early atherosclerotic lesions. J Clin Invest. 1997;100(11):2680-2690.

106. Napoli C, Glass CK, Witztum JL, Deutsch R, D’Armiento FP, Palinski W. Influence of maternal hypercholesterolaemia during pregnancy on progression of early atherosclerotic lesions in childhood: Fate of Early Lesions in Children (FELIC) study. Lancet. 1999;354(9186): 1234-1241.

107. Palinski W, Napoli C. The fetal origins of atherosclerosis: maternal hypercholesterolemia, and cholesterol-lowering or antioxidant treatment during pregnancy influence in utero programming and postnatal susceptibility to atherogenesis. FASEB J. 2002;16(11):1348-1360.

108. Philips DIW. Programming of the stress response: a fundamental mechanism underlying the long-term effects of the fetal environment? J Intern Med. 2007;261(5):453-460. 
International Journal of Women's Health

Dovepress

\section{Publish your work in this journal}

The International Journal of Women's Health is an international, peer- a very quick and fair peer-review system, which is all easy to use. reviewed open-access journal publishing original research, reports, editorials, reviews and commentaries on all aspects of women's healthcare including gynecology, obstetrics, and breast cancer. The Visit http://www.dovepress.com/testimonials.php to read real quotes from published authors.

manuscript management system is completely online and includes

Submit your manuscript here: http://www.dovepress.com/international-journal-of-womens-health-journal 